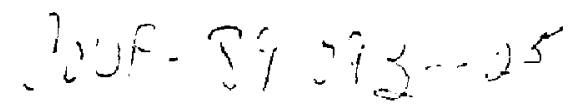

UCLA $/ P P G=-1256$

DE90 006334

\title{
Spectroscopic Studies of Carbon Impurities in PISCES-A
}

\author{
Y. Ra, A. Pospieszezyk*, Y. Hirooka, \\ W.K. Leung, R.W. Conn
}

UCLA-PPG-\#1256

August, 1989

\section{DISCLAIMER}

\begin{abstract}
This esport was prepared as an accoun1 of work sponsored by an agency of the United States Government. Neither the Unitod States Government nor any agency thsteot, nor any of their employees, makes any warranty, express or implied. or assumes any legal liability or responsibility for the accuracy, completeness, or usefulness of any information, appafalus, product, or process diselosed, or represents that its use would not infringe privately owned rights. Reference herein 10 any specific commercial produst. process, or service by trade name. If ademark. manufacturet, of otherwise does nol necessarily conslitute or imply its endorsement. tecornmendation, or Favoring by the Unifed States Government or any agency thereof. The views and opinions of authors expressed herein do nol necessarily slate of teflect those of the United States Government or any agency thereol.
\end{abstract}

\section{Institute of Plasma and Fusion Research University of California, Los Angeles Los Angeles, CA 90024}

*Institut fuer Plasmaphysik, Association EURATOM-KFA, Kernforschungsanlage, Juelich GmbH Postrach 1913, 5170 Juelich, FRG

Presented at the 36th National Symposium of American Vacuum Society, Boston, 1989.

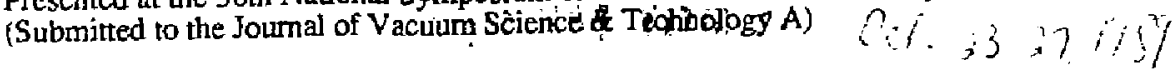




\title{
Spectroscopic Studies of Carbon Impurities in PISCES-A
}

\author{
Y. Ra, A. Pospieszczyk*, Y. Hirooka, W.K. Leung, R.W. Conn. \\ Institute of Plasma and Fusion Research \\ Department of Mechanical, Aerospace and Nuclenr Engineering. \\ Universiry of California, Los Angeles, Califomia 90024, USA \\ * Institut fír Plasmaphysik, Association EURATOM-KFA, \\ Kernforschungsanlage, Julich $\mathrm{GmbH}$ \\ Postfach 1913, 5170 Julich, FRG
}

\begin{abstract}
The graphite used for the limiter of the tokamak reactor produces carbon-containing molecular impuritics as a result of the interactions with the edge plasma. The behavior of these molecular impurities has been studied using emission spectroscopy. The present study includes: (1) finding molecular bands and atomic lines in the visible spectral range which can be used for the study of the molecular impurities, (2) studying the breakup processes of the molecular impurities on their way from the source into the plasma, (3) developing a spectroscopic diagnostic method for the absolute measurement of the inolecular impurity flux resulting from graphite erosion. For these studies, carbon-containing molecules such as $\mathrm{CH}_{4}, \mathrm{C}_{2} \mathrm{H}_{2}, \mathrm{C}_{2} \mathrm{H}_{4}, \mathrm{CO}$ and $\mathrm{CO}_{2}$ were injected into the tokamak-boundary-like plasma generated by PISCES-A. The spectrograms of these gases were taken. many useful bands and lines were determined from the spectrograms. The breakup processes of these gases were sutdied by observing the spatial profiles of the emission of the molecules and their radicals for different plasma conditions. For the absolute measurement of the eroded molecular impurity flux, the photon efficiency of the lines and bands were found by


measuring the absolute number of the emitted photons and injected gas molecules. The chemical sputtering yield of graphite by hydrogen plasma was spectroscopically measured using the previously obtained photon efficiencies. It showed good agreement with results obtained by weight loss measurements. 


\section{INTRODUCTION}

Emission spectroscopy has been widely used for the study of metallic impurities at rokamak boundary regions. This technique has been used for the identification of the impurity sources, ${ }^{1}$ the absolute measurement of impurity fluxes into the reactor plasma ${ }^{2.3}$ and their transport. ${ }^{4}$ However, the measurements are more difficult in present-day tokamak reactors which use graphite as the first wall and limiter materials. Due to chemical sputtering, graphite emits carbon-containing molecular impurities. The spectra from these molecules is much more complicated than those from atoms because of the presence of many band systems arising from vibrational and rotational transitions. The spectroscopical data for these molecules is limited and the use of spectroscopy in studying molecular impurities is difficult. However, emission spectroscopy can still serve as an useful diagnostic technique if the proper spectroscopical data for these molecules are available. In particular, it can be used to measure the influx of molecular impurities, ${ }^{5}$ to identify their sources and to study their break-up processes.

In the present work, an effort is made to provide the spectra and the spectroscopic data base for carbon-containing molecules and their radicals so as to make emission spectroscopy applicable in molecular impurity studies. For this, carbon-containing molecular impurities were injected into a tokamak-boundary-jike plasma generated by the PISCES-A facility. The experiment consists of three parts. Firstly, spectra for each gas were recorded for different plasma conditions. The reason for this was to find radiation bands and lines with reasonable intensities which could be used for the other part of the experiment. Also, it helps interpretation of spectra taken in tokarnak reactors which were difficult to interprete so far. Secondly, the penetration depths of the injected molecules and thier radicals were measured to study the break-up processes, which are important in understanding hydrogen and oxygen fueling. Finally, the ratios of decay to excitation rates of each molecules, the so-called "photon efficiency", were obtained. Details will be described in the following section. Absolute measurements of molecular impurity fluxes were therefore possible. In order to check the accuracy of spectroscopic measurements, the carbon sputtering yield was 
measured spectroscopically and compared with the previous experimental result which used weight loss method.

\section{EXPERIMENTAL PROCEDURE}

\section{A. Gas Injection Experiment}

A plasma with parameters close to those of a tokamak boundary layer was produced by the PISCES-A facility at UCLA. ${ }^{6}$ The PISCES-A facility is a linear plasma generator using a reflex are discharge methor. Throughout the present work, He plasma was used in order to avoid possible inteference with molecular spectra by the emission from the background gas. The plasma was diagnosed by a water-cooled Langmuir probe and a fast scanning probe. ${ }^{7}$ The characteristics and parameters of PISCES-A plasma have been discussed in detail elsewhere. ${ }^{6}$ To simulate the interactions of carbon-containing molecules with the plasma, hydrocarbon and carbonoxide molecules such as $\mathrm{CH}_{4}, \mathrm{C}_{2} \mathrm{H}_{2}, \mathrm{C}_{2} \mathrm{H}_{4}, \mathrm{CO}$ and $\mathrm{CO}_{2}$ were injected. These molecules are suspected to be the dominant products of chemical sputtering of graphite by hydrogen and oxygen. The experimental setup is shown in figure (1). A gas injector was built for blowing these molecules into the PISCES-A chamber. The molecules from the gas bottle flowed into a differentially pumped gas line $(\phi=2 \mathrm{~mm})$. The flow rate was controlled by a needle valve. At the tip of the molybdenum nozzle, there was a slit aperture which was $9.5 \mathrm{~mm}$ high and $4 \mathrm{~mm}$ wide. This geometry was chosen to minimize the dispersion effect of injected molecules. Figure (2) shows a photograph of $\mathrm{C}_{2} \mathrm{H}_{2}$ and $\mathrm{CO}$ gas injection into He plasma. The radiation from the injected gas molecules can be seen as a localized cloud in front of the nozzle. The strong localization is due to the short mean free paths of gas molecules in the plasma $(\cong 1 \mathrm{~cm})$. The flow rate of the molecules was measured by a baratron installed in the line. By considering the gas line as a long capillary tube, the flow rate $Q$ is given by

$$
\mathrm{Q}=\Delta \mathrm{P} \cdot \mathrm{C},
$$


where $\Delta \mathrm{P}$ is the pressure difference between the gas line and the chamber and $\mathrm{C}$ is the conductance of gas line. The gas line pressure was changed from 4 to 8 torr so that the molecular flow was a viscous flow. The conductance is given by ${ }^{8}$

$$
\mathrm{C}=1.64 \times 10^{-2} \frac{\mathrm{D}^{4}}{\eta \mathrm{L}} \Delta \mathrm{P}(\text { liter } / \mathrm{sec}),
$$

$\mathrm{D}$ and $\mathrm{L}$ are the diameter and the length of the pipe in [cm], $\Delta \mathrm{P}$ is given in [Torr]. $\eta$ denotes the viscosity which is given by

$$
\eta=2.71 \times 10^{-21} \frac{\sqrt{\mathrm{MT}}}{\sigma^{2}}(\mathrm{~g} / \mathrm{cm} \mathrm{sec})
$$

where $M$ is mass of the molecule in [amu], $T$ is the temperature in $~^{\circ} \mathrm{K}$ ] and $\sigma$ is the diameter of the molecule in [cm]. Since the chamber pressure was in the range of $10^{-4}$ tor, the upstream pressure measured by the baratron practically determined the flow rate.

The radiation was observed with a 1.33 meter Czemy-Turner type optical spectrometer, which had a grating of 1200 grooves/mm resulting in a linear dispersion of $6 \AA / m m$. The optical setup was made in such a way that the spectrometer viewed a narrow region along the chamber axis as shown in fig (2). The spectra of injected molecules were recorded by a camera attached at the exit slit of the spectrometer. High speed polaroid film (ISO $3000 / 36^{\circ}$ ) was used with a spectral sensitivity of the film from $3000 \AA$ up to $7000 \AA$. The recordings provided both spatial and spectral informations.

For the quantitative measurement of the photon emission integrated along the line-of-sight, a photomultiplier tube (PMT) was used. The bands and lines beyond the sensitivity of the PMT were measured by an optical multichannel analyser (OMA). The OMA had a linear array (S-type) of 1024 pixels, which in combination with the spectrometer gave spectral resolution of $0.15 \AA$. Both PMT and OMA were absolutely calibrated with respect to a standard tungsten ribbon lamp. The brightness of the integrated photon emission can be converted into flux if the atoms are lost via 
jonization within the line-of-sight ${ }^{2}$. Molecular impurity flux can be measured in a similar manner. If most of the injected molecules of gas $\mathrm{A}$ are lost by either ionization or dissociation rather than escaping out of the plasma, the flux of the injected molecules $\Psi_{A}(r)$ can be expressed as ${ }^{9}$

$$
\Psi_{A(r)}=\frac{4 \pi}{\Gamma} B_{t o t} \frac{<\sigma_{t o t} v_{e}>(T)}{<\sigma_{e x} v_{e}>(r)},
$$

where $\Gamma$ is the branching ration, $B_{\text {tot }}$ is the brightness of photon emission due to electron collisions, $<\sigma_{\text {tot }} \mathrm{ve}^{\mathrm{e}}>$ is the total loss rate of molecules, $\left\langle\sigma_{\mathrm{ex}} v_{\mathrm{e}}\right\rangle$ is the excitation rate for a certain band or line. Equation (4) can be rearranged as

$$
\frac{\Psi_{\mathrm{A}}(\mathrm{r})}{4 \pi \mathrm{B}_{\text {tot }}}=\frac{<\sigma_{\text {tot }} \mathrm{v}_{\mathrm{e}}>(\mathrm{r})}{\left\langle\sigma_{\mathrm{ex}} \mathrm{v}_{\mathrm{e}}>(\mathrm{I})\right.} \equiv \gamma,
$$

$\gamma$ defines a photon efficiency for a certain band for gas $\mathrm{A}$. If the photon efficiency is known, the flux of injected molecules can be determined absolutely by measuring $\mathbf{B}_{\text {tot. }}$. Spatially resolved emission profiles for a single band or line could oe obtained by rotating the OMA $90^{\circ}$ from its normal position.

\section{B. Spectroscopic Measurement of Chemical Sputtering Yield}

In order to demonstrate the capability of the spectroscopic determination of molecular flux and to check the validity of the obtained photon efficiency, the chemical sp:ttering yield was measured spectroscopically. The gas injector was replaced by a graphite sample. The sample was water-cooled for low temperatures $\left(5500^{\circ} \mathrm{C}\right)$ and air-cooled for higher temperature operations. The sample temperature was controlled by adjusting the cooling rate. The same oprical setup for the gas injection experiment was used. To use the spectroscopic method, the molecules emilted from graphite should be completely attenuated within the plasma. This is only achieved if the plasma dimension is much bigger than that of the sample. However, this was not possible since 
the achievable plasma dimension was limited and the sample could not be made indefinitely small. Instead, the sample was made as large as the size of plasma and the brightness integrated along the line-of-sight at the center of the sample was measured. However, brightness at the center was not a directly measurable quantity. In order to obtain this, the measured brightness profile had to be Abel-inverted. ${ }^{10-12}$ For the measurement, the absolutely calibrated optical multichannel analyser (OMA) was used. The spatial profile was obtained by a scanning mirror.

\section{RESULTS and DISCUSSION}

\section{A. Molecular Spectrum}

The spectra of injected molecules were recorded for two different plasma conditions: high density $\left(\cong 5 \times 10^{12} / \mathrm{cm}^{3}\right)$, low temperature $(\cong 10 \mathrm{ev})$ and low density $\left(\cong 5 \times 10^{12} / \mathrm{cm}^{3}\right)$, high temperature $(\cong 30 \mathrm{ev})$. This was to simulate two different conditions of a tokamak boundary layer plasma. The spectrogram of $\mathrm{C}_{2} \mathrm{H}_{2}$, shown in fig (3), can serve as an example for a hydrocarbon spectrum. The $\mathrm{CH}$ band system with its $\mathrm{Q}$ head of the $(0,0)$ band at $4314.2 \AA$ is an already wellknown system. It is referred to as the "4300A system" $\left(A^{2} \Delta-X^{2} \Pi\right)$. Its lower wave length tail is merged with the $(0,0)$ band of the Douglas-Herzberg system $\left(A^{l} \Pi-X^{l} \Sigma\right)$ from $\mathrm{CH}^{+}$. Another band system of the CH radical appears around $3900 \AA$. It is the "3900 $\AA$ system" $\left(B^{2} \Delta-X^{2} \Pi\right)$. Both band systems of $\mathrm{CH}$ radical are strong and not much blended by other bands so that they can be used for further studies. $C_{2}$ molecular bands can be seen through the entire range. The band system from $C_{2}$ in the lower wave length is the Deslandres-d Azambuja system $\left(c^{l} \Pi_{\gamma} b^{l} \Pi_{v}\right)$ and the one in the upper wave length is the Swan system $\left(A^{3} \Pi_{\gamma}-X^{3} \Pi_{v}\right)$. Lines from hydrogen $\left(H_{\alpha}\right.$, $\mathrm{H}_{\beta}, \mathrm{H}_{\gamma}$ ) and carbon (CI, CII) also appear. Other hydrocarbons show similar spectra with additional bands. The spectrum of $\mathrm{CH}_{4}$ shows a methylene radical band system $\left(\mathrm{b}^{1} \mathrm{~B}_{1}-\mathrm{a}^{1} \mathrm{~A}_{1}\right)$. Suprisingly, $\mathrm{C}_{2}$ bands can be detected in the spectrum of $\mathrm{CH}_{4}$. It is not clear if the $\mathrm{C}_{2}$ bands are really from $\mathrm{CH}_{4}$ or from impurities in the background gas. Hydrocarbon spectra do not change very much with respect to temperature. Attenuation lengths of barids and lines appears to be shorter at high temperature. Fig (4) shows the spectra of $\mathrm{CO}$ for low temperature. Many band 
systems from $\mathrm{CO}$ and $\mathrm{CO}^{+}$can be seen. The comet tail system $\left(\mathrm{A}^{2} \Pi-\mathrm{X}^{2} \Sigma\right)$ from $\mathrm{CO}^{+}$can be observed over the whole wave length range. It has two strong $\mathbf{R}$ heads with corresponding $\mathbf{Q}$ heads lying from 5 to $1.5 \AA$ to the red of the $R$ heads. Around $6000 \AA$, many band systems from $C O$ appear strongly blended. These band systems are the triplet bands $\left(d^{3} \Delta-a^{3} \Pi\right)$, the Asundi bands $\left(a^{3} \Sigma-a^{3} \Pi\right)$ and the Angström system $\left(B^{1} \Sigma-A^{1} \Pi\right)$. At high temperature, these bands are weakly visible and the comet tail system becomes prominent. The identified band systems are given in table (1). Some of the strong bands were used for the following experiments. Based upon the obtained spectra, the spectrum taken in front of the TEXTOR limiter ${ }^{1}$ was reinterpreted. It was possible to identify bands which could not have been identified so far. The most valuable result was the identification of $\mathrm{CO}$ and $\mathrm{CO}^{+}$aound $6000 \AA$ which were originally assumed to originate from $\mathrm{D}_{2}$. The appearance of bands from carbonoxides indicates that these molecules play an important role in the transport of carbon and oxygen in a tokamak with carbon surroundings. More information for the other molecules injection can be found in reference (9).

\section{B. Break-Up Processes}

The breakup processes of injected carbon-containing molecules were studied by observing the spatial profiles of radiation from molecules and their radicals. For instance, the density profile of the CH radical can be found by measuring the spatial emission profile in the light of the $4300 \AA$ system. In such a way, the whole chain of break-up processes can be studied if the appropriate radicals can be spectroscopically identified. The experiment was carried out for three different electron temperature conditions (about $10 \mathrm{ev}, 25 \mathrm{ev}$ and $35 \mathrm{ev}$ ). The background was measured by turning off the gas injection. The obtained brightness profile by the OMA was deconvoluted with the apparatus function which was obtained by using HeI lines in the same wave length range. The brightness profiles of bands and lines from $\mathrm{CH}_{4}$ at $8.1 \mathrm{ev}$ are shown in fig. (5). The $\mathrm{H}_{\alpha}$ line has its peak closest to the nozzle, indicating that hydrogen is the first particle broken out of $\mathrm{CH}_{4}$. Most of the peaks appear very close to each other within $2 \mathrm{~cm}$ from the nozzle. As expected, the peaks appear in the sequence of $\mathrm{CH}_{2}, \mathrm{CH}$ and $\mathrm{CI}$. It suggests that $\mathrm{CH}_{4}$ will lose hydrogen as it ravels 
through the plasma until only carbon remains. The CII peak was found to be closer to the nozzle than Cl. This might be due to presheath-effects developing in front of the nozzle. High order hydrocarbons show similar profiles except that they have shorter penetration depths than $\mathrm{CH}_{4}$. This means that $\mathrm{CH}_{4}$ can most affect hydrogen and carbon fueling in a tokamak reactor. Mostly, the emission from carbonoxides is strongly localized in front of the nozzle. 'The penetration depths of all molecules were found within a couple of $\mathrm{cm}$. This short penetration depths support the previous assumption that the most of the injected molecules were attenuated within the plasma in the absolute measurement of molecular influx. Aiso, the results can provide a good experimental background for computer simulations trying to solve the complete break-up processes. ${ }^{13}$ More information for the other molecules can be found in reference (9).

\section{Photon Efficiencies}

Equation (5) shows that the intensity of the photon emission $B_{\text {tot }}$ and the injection rate of molecules $\Psi_{\mathrm{A}}$ need to be measured to get the photon efficiencies. The total integrated photon

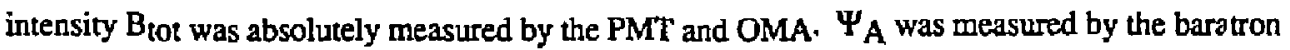
as described in the previous section. The first experimental data on the photon efficiencies of carbon-containing molecules were obtained for different molecular injection rares. For lower fluxes, the resulting molecular density was about $8 \times 10^{11}-1.1 \times 10^{13} \mathrm{~cm}^{-3}$ and for high fluxes, $4.5 \times 10^{13}-2.0 \times 10^{14} \mathrm{~cm}^{-3}$. Since the molesular density is locally higher than electron density in the high flux case, the electron temperature measurements might have a small error especially in the high temperature case. Unfortunately, aitering electron temperature and density separately was not possible. These two conditions were closely coupled. The $\mathrm{CH}$ band intensity for various densiiy and temperature sets was measured to test how the enission behaved. It was found that the temperature plays a more important role in the photon emission than the density. For the measurement of the photon efficiencies, the sirongest band from each molecule found in section III.A. was selected. Some of them were particularly chosen considering the observability in a tokamak boundary. Examples of the photon efficiencies obtained are presented in fig are (6). To 
check the validity of the data, the photon efficiency of the $4300 \AA \mathrm{CH}$ band system from $\mathrm{CH}_{4}$ (figure (6.a)) is compared with an estimate based upon the excitation cross-section from reference (14) and the loss rates from reference (15). The estimate agrees very well with the experimental results. Unfortunately, such a comparison could not be made for carbonoxides. Unlike the photon efficiency for atoms, the obtained photon efficiency for molecules may have a minimum as it is seen in figures (6.b) and (6.c). The minimum point is supposedly due to the threshold energy for the dissociation of molecules. Photon efficiencies for $\mathrm{CO}$ bands from $\mathrm{CO}$ molecules behave evidently as in the case of atoms(figure (6.d)).

\section{Chemical Sputtering Yield}

The $4300 \mathrm{~A}$ system of the $\mathrm{CH}$ radical was used to measure the $\mathrm{CH}_{4}$ erosion from $\mathrm{POCO}$ graphite by a hydrogen plasraa. The diameter of the saiuple was 2 inches, which was about the size of the plasma. The tempera $u r e$ of the sample wiss varied from 100 to $800^{\circ} \mathrm{C}$. The emission profile was obtained by a scanning mirror. The obtained emission profile was fitted by a polynomial and ther: lisel-inverted. The incident ions were assumed to have a uniform distribution ovar the sample surfece so that $\mathrm{CH}_{4}$ molecules were homogeneously eroded from the surface as the main products of chemical sputtering. The photon efficiency $\mathrm{g}$ for the $\mathrm{CH}$ band was read from fig. (6.a). The erosion yield $Y$ can be expressed as ${ }^{5}$

$$
\mathrm{Y}=\mathrm{\gamma} \frac{\mathrm{B}_{\mathrm{iOt}}}{\mathrm{J}_{\mathrm{H}^{+}}}
$$

where $\mathrm{J}_{\mathrm{H}^{+}}$is the incident proton flux. $\mathrm{J}_{\mathrm{H}^{+}}$was measured by a Langmuir probe siturated around $1 \mathrm{~cm}$ apart 1 rom the sample. In the present experiment, the incident piasma had a flux of $1.3 \times 10^{18}$ $\mathrm{H}^{+} / \mathrm{cm}^{2} \mathrm{sec}$ and the electron temperature was $10 \mathrm{ev}$. The result for the spectroscopically measured chemical sputtering yield is presented in fig (7). The result is compared with previous measurement for a flux of $1.5 \times 10^{18} \mathrm{H}^{+} / \mathrm{cm}^{2}$ sec. $^{16}$ For the measurement of the yield, the weight loss method was used. Thus, the measured trosion yield represents the total yield including hoth 
chemical and physical sputtering. At high temperature $\left(\cong 500^{\circ} \mathrm{C}\right)$ where chemical sputtering is dominant, two results agree very well. This enhances the confidence in the accuracy of obtained photon efficiencies and the validity of the spectroscopic method.

\section{SUMMARY}

The spectroscopic database for the carbon-containing molecules was obtained. From the spectra of the molecules in tha plasma boundary condition, many useful band systems for spectroscopic studies were found. The TEXTOR spectrum could be interpreted by the obtained spectra. Many bands of $\mathrm{CO}$ and $\mathrm{CO}^{+}$were found from the spectrum, which indicates carbonoxides are important in carbon and oxygen transport. The penetration depths of the molecules and their radicals were measured for the study of break-up processes of the molecules. The photon efficincies of many bands and lines from the molecules were obained. The absolute measurement of molecular impurity influx was made possible by the obtained photon efficiencies. Chemical sputtering yield was measured spectroscopically and compared with the previous measurment. It was shown that the spectroscopic measurement is accurate. 


\section{REFERENCES}

1 A. Pospieszczyk, H.L. Bay, P. Bogen, H. Hartwig, E. Hintz, L. Konen, G.G. Ross, D.

Rusbuldt, U. Samm, and B. Schweer, I. Nucl. Mater., 145/147 (1987), 547

2 C.S. Pitcher, G.M. McCracken, D.H.J. Goodall, A.A. Haasz, G.F. Mathews, P.C.

Stangeby, Nucl. Fusion, 26 (1986), 1641

3 K.H. Behringer, J. Nucl. Mater, 145/147 (1987),145

4 D.H.J. Goodall, S.J. Fielding, C.S. Pitcher, J. Allen and G.M, MaCracken, J. Nucl. Mater., $145 / 147(1987) 596$

S Y. Hirooka, A. Pospieszczyk, R.W. Conn, B. Mills, R.E. Nygren, and Y. Ra, J. Vac. Sci. Technol., A 7 (3) (1989), 1070

6 D.M. Goebel, G.A. Campbell, and R.W. Conn, J. Nucl. Mater., $111 / 112$ (1982), 457

7 R. Lehmer, B. LaBombard, R. W. Conn, UCLA-PPG-1228 (1989)

8 A. Roth, Vaccun Technology, (North-Lolland Publishing Comp., 1976)

9 A. Pospieszczyk, Y. Ra, Y. Hirroka, R.W. Conn, D.M. Goebel, B. Labombard, R.E. Nygren, UCLA-PPG-1251(1989)

10 K.Bockasten, J. Opt. Soc. Am., 51(1961), 943

11 W.L. Bar, J. Opt. Soc. Am., 52(1962), 885

12 N. Gottardi, J. Appl. Phys., 50 (1979), 2647

13 J.T. Hogan, C.C. Klepper, D.L. Hillis and T. Uckan, J. Nucl. Mater., 162-164(1989), 469

14 G.R. Möhlmann and F.J. deHeer, Chem. Phys. 19(1977), 233

15 A. B. Ehrhardt and W.D. Langer, PPPL-2477, Princeton Univ.(1987)

${ }^{16}$ D.M. Goebel, J. Bohdansky, R.W. Conn, Y. Hirooka, B. LaBombard, W.K. Leung, R.E. Nygren, J. Roth, G.R. Tynan, Nucl. Fusion, 28(1988), 1041 
Table 1. The molecular band systems found from the spectra of carbon-containing molecules. The number in the left column is the identification number for the bands in spectrograms.

\begin{tabular}{|c|c|c|c|}
\hline & Type & Band System & Transition \\
\hline 1 & $\mathrm{CO}^{+}$ & Comet tail system & $A^{2} \Pi-X^{2} \Sigma$ \\
\hline 2 & $\infty O$ & Angström system & $B^{1} \Sigma-A^{1} \Pi$ \\
\hline 3 & $C_{2}$ & Swan system & $A^{3} \Pi_{g}-X^{3} \Pi_{u}$ \\
\hline 4 & $\mathrm{C}_{2}$ & Deslandres-d'Azambuja system & $c^{1} \Pi_{g}-b^{1} \Pi_{u}$ \\
\hline 5 & $\mathrm{CH}$ & $43000 \AA$ system & $\mathrm{A}^{2} \Delta-\mathrm{X}^{2} \Pi$ \\
\hline 6 & $\mathrm{CH}$ & $3900 \AA$ system & $B^{2} \Sigma-X^{2} \Pi$ \\
\hline 7 & $\mathrm{CH}_{2}$ & Methylene radical & $b^{1} 3_{1}-a^{1} A_{1}$ \\
\hline 8 & $C O$ & The Triplet bands & $\mathrm{d}^{3} \Delta-\mathrm{a}^{3} \Pi$ \\
\hline 9 & $\mathrm{CO}$ & Third Positive bands & $b^{3} r-a^{3} \Pi$ \\
\hline 10 & $\mathrm{CO}^{+}$ & Baldet-Johnson system & $B^{2} \Sigma-A^{2} \Pi$ \\
\hline 11 & $\infty$ & Asundi bands & $a^{3} \Sigma-a^{3} \Pi$ \\
\hline 12 & $\mathrm{CO}$ & 5B bands & $b^{3} \Sigma-a^{3} \Pi$ \\
\hline 13 & $\mathrm{CO}$ & Herman bands & $e^{3} \Sigma^{-}-a^{3} \Pi$ \\
\hline 14 & $\mathrm{CO}_{2}^{+}$ & Fox, Duffendack and Barker's system & $A^{2} \Pi-x^{2} \Pi$ \\
\hline 15 & $\mathrm{CO}_{2}^{+}$ & Bands 112883 and 112896 & $\mathrm{~A}^{2} \Sigma^{+}-X^{2} \Pi$ \\
\hline 16 & $\mathrm{CO}_{2}$ & CO flame bands & ${ }^{1} B_{2^{-}} X^{1} \Sigma^{+}$ \\
\hline 17 & $\mathrm{CO}^{+}$ & Douglas-Herzberg system & $A^{2} \Pi-X^{2} \Sigma$ \\
\hline
\end{tabular}




\section{Figure Captions}

Fig.1. (upper left) $\mathrm{C}_{2} \mathrm{H}_{2}$ gas Injecion, (upper right) $\mathrm{C}_{2} \mathrm{H}_{2}$ gas injection with an interfernce filter $\left(\lambda_{c}=4250 \AA\right.$, FWHM $\left.=50 \AA\right) 4300 \AA$ syster: of $\mathrm{CH}$ radical can be seen. (lower left) $\mathrm{CO}$ gas injection, (lower right) $\mathrm{CO}$ gas injection with the same interference filter. $\mathrm{CO}^{+}$ band (Baldet-Johnson system) and $\mathrm{CO}$ band (Angström system) can be seen.

Fig.2. The experimental setup for the gas injection experiment.

Fig.3. A spectrogram of $\mathrm{C}_{2} \mathrm{H}_{2}$. The horizontal axis is wave length $(\AA)$ and the spatial information is given in the vertical axis. $\mathrm{T}_{\mathrm{e}}=30 \mathrm{ev}, \mathrm{n}_{\mathrm{e}}=1 \times 10^{12} \mathrm{~cm}^{-3}$.

Fig. 4. A spectrogram of $C O . T_{e}=10$ ev, $n_{e}=5 \times 10^{12} \mathrm{~cm}^{-3}$.

Fig. 5. The Brightness profiles of lines and bands from $\mathrm{CH}_{4} . \mathrm{T}_{\mathrm{e}}=8.1 \mathrm{ev}, \mathrm{n}_{\mathrm{e}}=5.17 \times 10^{12} \mathrm{~cm}^{-3}$.

(a) $\mathrm{CI}$, (b) $\mathrm{CH}$, (c) $\mathrm{CH}_{2}$. (d) $\mathrm{H}_{\alpha}$, (e) $\mathrm{CH}^{+}$and (f) $\mathrm{CII}$

Fig. 6. Photon Efficiencies: (a) $\mathrm{CH}$ band (4300 system) from $\mathrm{CH}_{4}$, (b) $\mathrm{H}_{\alpha}$ from $\mathrm{CH}_{4}$, (c) OI from $\mathrm{CO}$, and (d) $\mathrm{CO}$ from $\mathrm{CO}$, (measurements were done for two different gas injection rates which were different for each gases ).

Fig. 7. Chemical sputtering yield. 
Fig.2

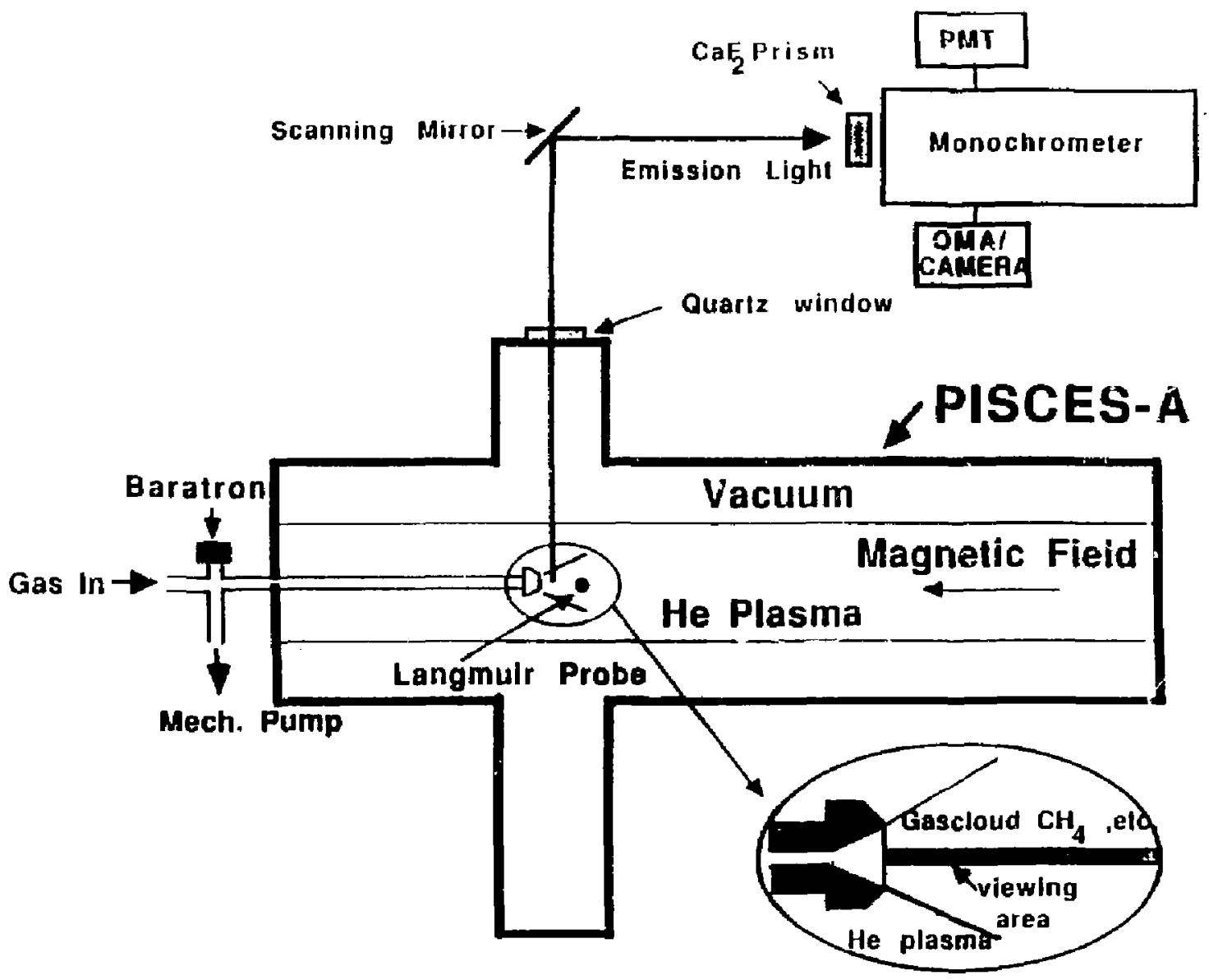




$$
|| \mid
$$




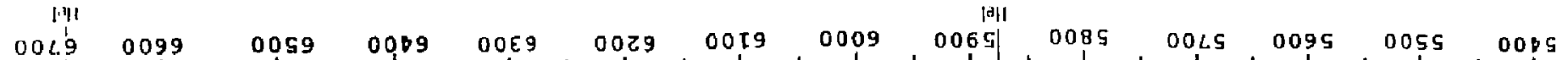

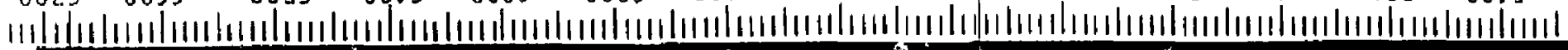

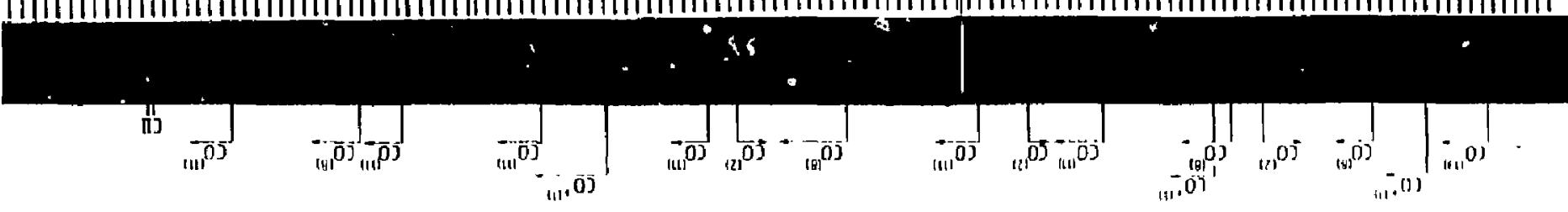

I매|매|매|

IaH $11 \mathrm{aH}$

INII IAll

lill

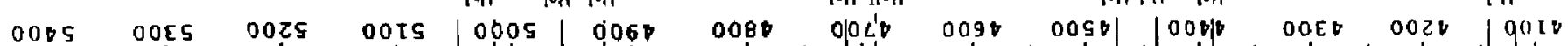

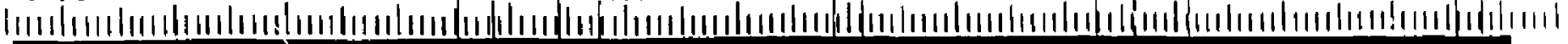

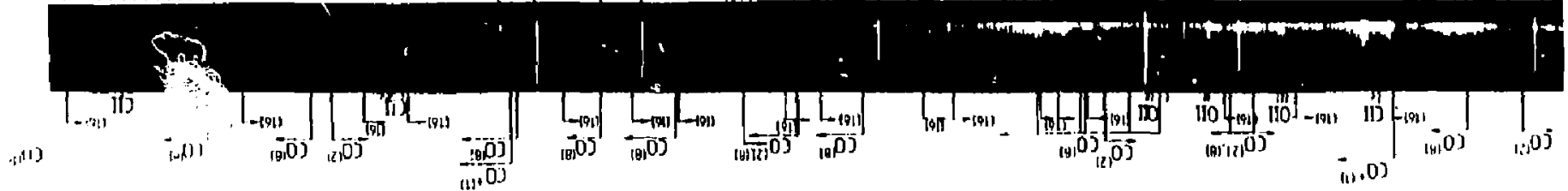

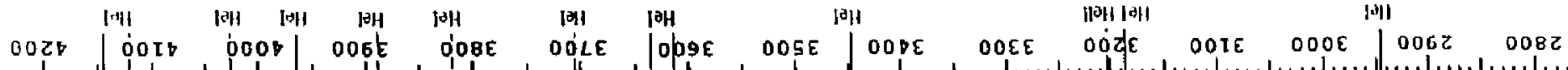

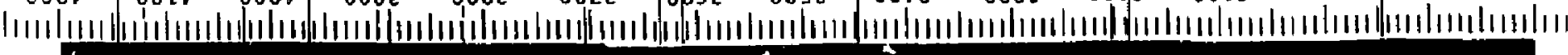

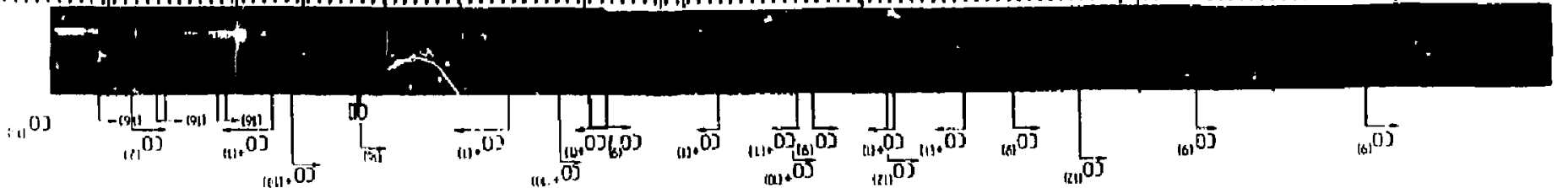

$\stackrel{\nabla}{\frac{\nabla}{4}}$ 

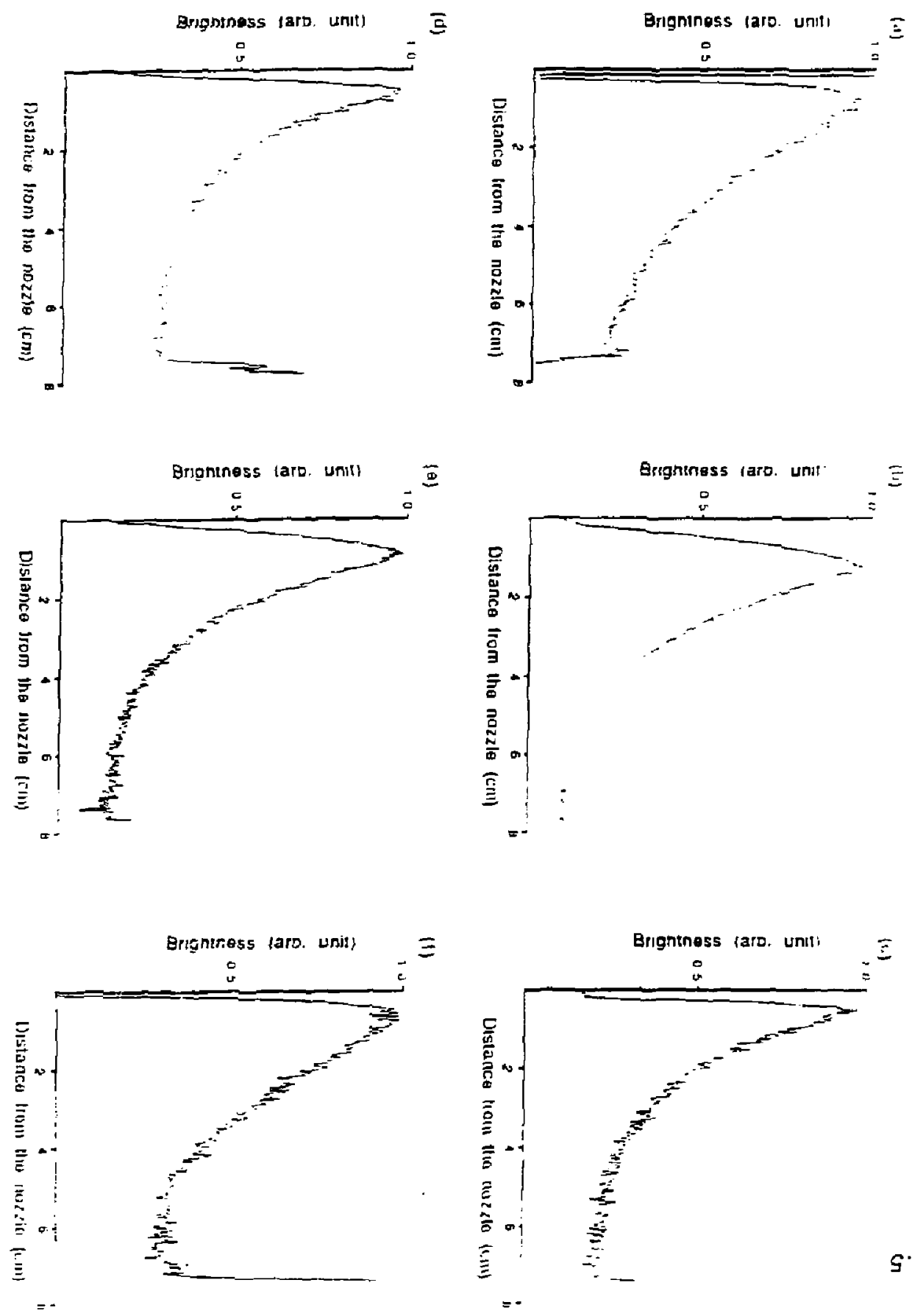

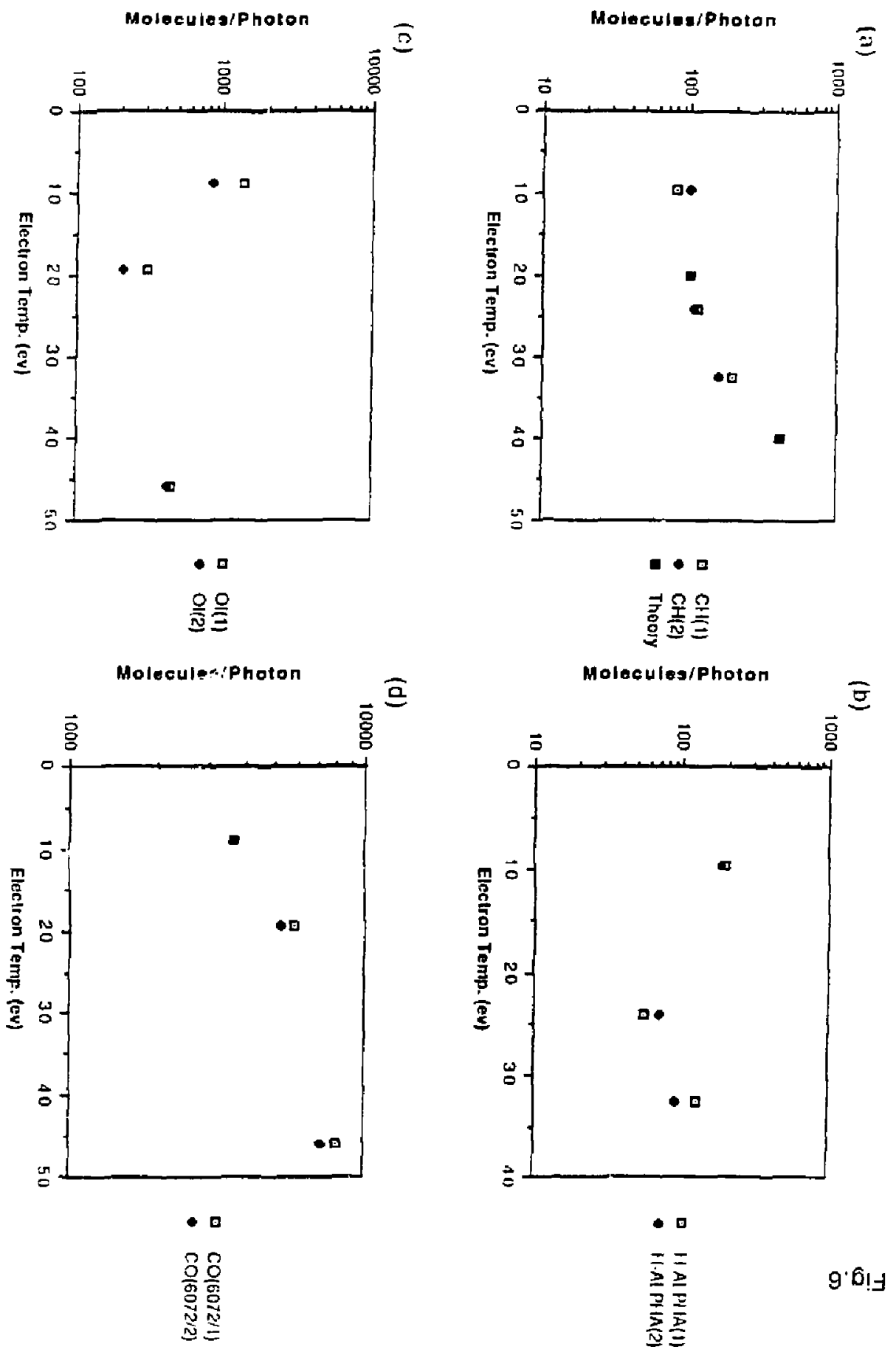
Fig.7

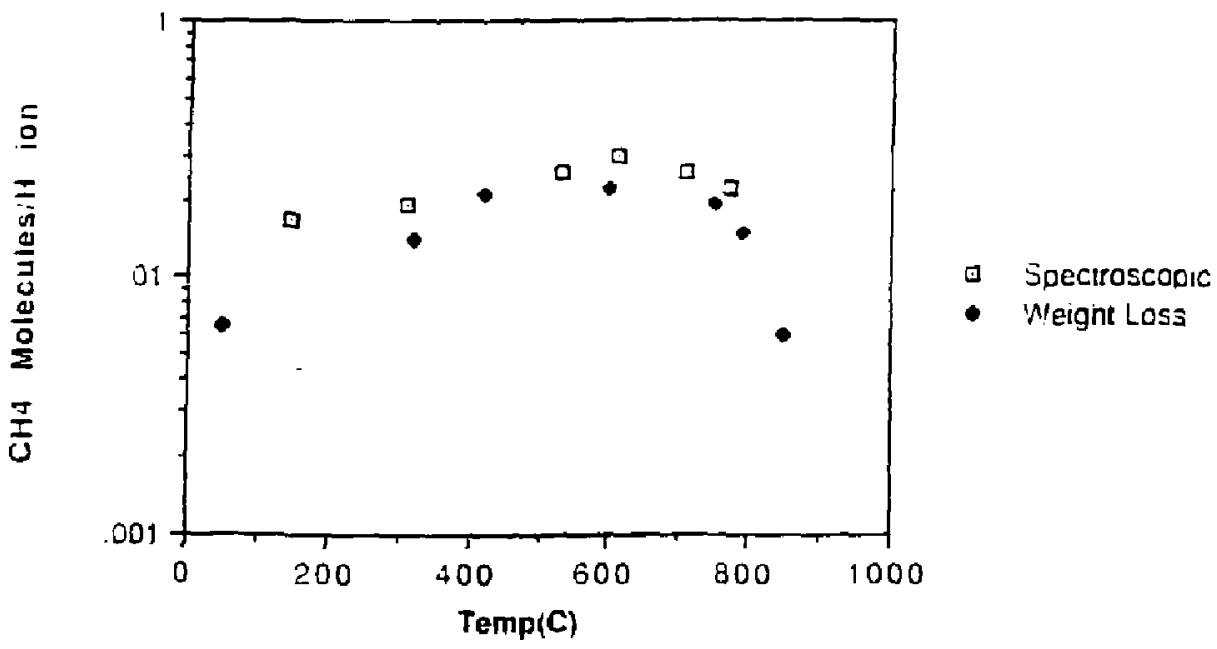

